\title{
El Estado, entre la modernización y el cambio
}

\author{
Joaquín Arriola y David Mena
}

\begin{abstract}
Resumen
La salida de Naciones Unidas colocará en el centro de la coyuntura el tema del Estado, por tanto, la discusión sobre el poder, eje de todo discurso político, se presenta como un reto. El dilema consiste en mantener un Estado subordinado al esquema económico dominante o un Estado promotor de consensos, de desarrollo y transformación social. Las fuerzas políticas y sociales del país están obligadas a tomar posición sobre la necesidad de refundar el Estado desde la perspectiva del desarrollo económico y social, para propiciar un nuevo modelo de acumulación de capital y de redistribución de la riqueza nacional.
\end{abstract}

\section{El Estado en cuarentena}

La firma de los acuerdos de paz abrió un período durante el cual el Estado se mantuvo en cuarentena: el proceso de paz ha sido condicionado por la tutela de Estados Unidos y Naciones Unidas, que han controlado el desarrollo de la vida institucional (ONUSAL), y por la orientación del gasto público, determinada por los organismos financieros internacionales y las agencias donantes (Fondo de Inversión Social y Secretaría de Reconstrucción Nacional).

La salida de Naciones Unidas colocará en el centro de la coyuntura el tema del Estado, por tanto, la discusión sobre el poder, eje de todo discurso político, se presenta como un reto del momento. En la izquierda esta discusión ha sido suplantada y disfrazada por la discusión de "los programas". No son casualidad los pleitos de los últimos meses sobre la corrupción, el tráfico de influencias, etc., entre los representantes de la derecha: están discutiendo cómo se debe realizar el ejercicio del poder y más específicamente del poder del Estado.

\section{Los cambios estructurales en la economía}

Los acuerdos de paz representan un importante cambio estructural en la política salvadoreña al reformar la Fuerza Armada, el poder judicial y al promover participación electoral irrestricta. El carácter de este cambio estructural significa, fundamentalmente, que no se ha cuestionado la legitimidad del Estado y, por lo tanto, del sistema político que lo acompaña. La pelea de la izquierda ya no tiene como objetivo la destrucción de los grupos que han detentado el poder del Estado, sino acceder al control de ese Estado, para hacer prevalecer los intereses de los sectores a quienes representan. 


\section{Todo apunta a que la derecha en el poder tiene interés en subordinar aún más las estructuras económicas nacionales al sistema productivo norteamericano.}

En el terreno de la economía solo hay dos cambios estructurales en la década de los noventa. Por un lado, la reprivatización del sistema bancario, que pasó a manos de grupos procedentes de la oligarquía cafetalera (Cristiani, Regalado, Dueñas, Alvarez) y del capital comercial de origen libanés (Simán), y se ha convertido en el medio principal de centralización y concentración del capital en un sector muy reducido del capital nacional.

Las remesas se han convertido en el otro factor fundamental que ha venido a modificar el comportamiento de la economía salvadoreña. El elevado monto que estos dólares "regalados" representan (junto a la ayuda externa, en torno al 20 por ciento del producto nacional) los ha convertido en el eje de la acumulación de capital en los últimos años, específicamente desde que Cristiani y su grupo llegaron al gobierno. Al controlar los dólares de los trabajadores migrantes por medio del sistema financiero, los propietarios de los bancos y de las casas de cambio adquirieron acceso garantizado a unos créditos en dólares, sin garantías reales - pues los bancos que conceden esos créditos son de su propiedad-, y así pueden disponer de un flujo de capitales para invertir en el extranjero, puesto que de otro modo no podrían obtener de la banca internacional.

La transnacionalización de una parte del capital salvadoreño es la principal consecuencia de la guerra y de la paz. Durante el conflicto, algunos grupos económicos sacaron sus capitales al exterior y aprendieron las nuevas reglas del juego capitalista internacional. Ahora, con la paz y las remesas, estos grupos capitalistas regresan para beneficiarse del control financiero de las mismas, obteniendo así acceso a un importante monto de divisas que capturan con el manejo del ahorro nacional y que les sirve para acelerar su proceso de transnacionalización, invirtiendo fuera del país.

\section{La hegemonía de Estados Unidos}

De los tres proyectos de sociedad en pugna (ver nuestros artículos en ECA, 1994, 521 y 536), el "modernizante" es el que se va imponiendo. Durante la década de la guerra, estos tres proyectos estuvieron confrontados; pero el inicio de las negociaciones de paz significó, en último término, el triunfo de uno de ellos. La negociación de la paz y los acuerdos son, ciertamente, un triunfo del pueblo salvadoreño, como proclaman todos los políticos, pero también una victoria política de Estados Unidos, que dominó dos proyectos: el tradicional oligárquico y el popular insurgente.

El liderazgo político de Estados Unidos sobre la coyuntura salvadoreña se enmarca en un proceso de cambios mundiales que, en lo económico, se caracteriza por una globalización que contiene un reforzamiento del poder del capital transnacional a costa de los capitales nacionales y de los trabajadores y un proceso de regionalización, en el cual las distintas potencias mundiales (Japón, Estados Unidos y la Unión Europea) se disputan el control político y económico de las diferentes regiones del mundo para facilitar la salida a la crisis interna que dura ya veinte años. En lo político, la coyuntura mundial está determinada por la derrota del socialismo comunista y por el triunfo del capitalismo como único horizonte histórico previsible para el futuro inmediatol.

Para iniciar la transición hacia la "normalización" del país en el contexto del proyecto norteamericano para la región, se volvió necesario garantizar la gobernabilidad, por medio de alianzas explícitas o tácitas con sectores sociales nativos. Para sacar adelante ese plan era necesario subordinar políticamente a la Fuerza Armada, la administradora tradicional del Estado.

En este contexto y para aplicar este esquema de dominación se reorientaron los diversos grupos políticos, intelectuales, laborales y económicos; pero en particular el partido ARENA, los grupos económicos más fuertes articulados al mismo y la cúpula del ejército. Estos últimos adoptaron como propio un proyecto en gran medida diseñado en Estados Unidos. Así, por un lado, impusieron las reglas formales del juego democrático (la división 
de los poderes, las elecciones y la alternancia en el ejecutivo, la pluralidad en el legislativo, la subordinación del ejército al poder civil, etc.) en El Salvador y, por el otro, iniciaron la aplicación del programa neoliberal de ajuste estructural.

La aplicación efectiva del modelo supondría cambiar las características del Estado para que lo firmado en los acuerdos de paz adquiera materialidad: en las formas de dominación, pasar de un dominio repre-

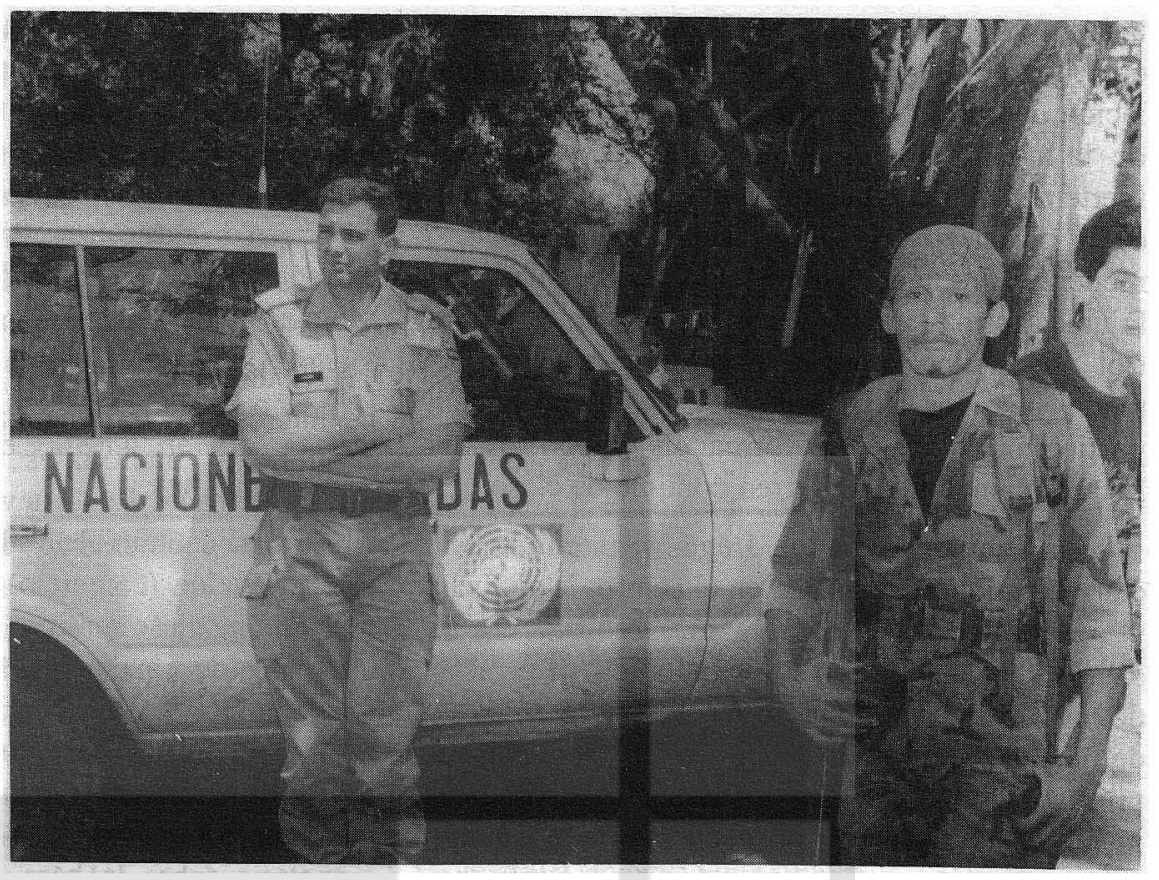
sivo a una hegemonía de consenso; en los mecanismos de regulación estatal de las actividades sociales y económicas, abrir ciertos espacios a los sectores productivos y a las organizaciones populares; en las formas de articulación de las clases al Estado y en el carácter político de la institución estatal, vigencia del Estado de derecho.

Esto se vuelve necesario porque, tradicionalmente, el Estado salvadoreño estaba al servicio de un modelo de acumulación basado en la agroexportación y en la economía de rentas, que no requería de "mucho Estado": la demanda interna no era importante, por lo tanto, no era necesario construir una clase media, ni pagar salarios suficientes... básicamente sólo se necesitaba el aparato represivo del Estado, para garantizar la paz social y la reproducción del orden establecido2.

El mercado común centroamericano fue resultado de la aparición, en la escena política y económica, de otro modelo de acumulación que requería a su vez otro modelo de Estado. El sector industrializante y modernizante peleó por su participación en el poder del Estado, para obtener la tutela necesaria que le permitiera acumular. Ahí estaba el límite de la modernización propuesta por los industrializantes, quienes, en la práctica, seguían

considerando al Estado como un instrumento al servicio del capital y, por lo tanto, un marco institucional subordinado a los requerimientos de la acumulación. La carencia de concreción política de este sector, se traducía en que no proponían otros modelos de Estado y, en ese sentido, la propuesta no era alternativa al modelo oligárquico agroexportador vigente hasta el momento. Los golpes de Estado de los años cincuenta y sesenta se inscriben en la disputa entre el núcleo oligárquico agroexportador y el sector industrializante, dos sectores que privilegiaban lógicas de acumulación diferentes, por controlar su poder.

El resultado fue un modelo de acumulación híbrido con un Estado siempre igual a sí mismo, un Estado "patrimonial" y orientado hacia el control social3. La debilidad de este esquema institucional y las contradicciones de poder no resueltas no pudieron producir un desarrollo adecuado de la industrialización nacional y erosionaron al mercado común centroamericano.

Un factor nuevo de poder en este período fue la aparición del capital extranjero, avalado por los Estados Unidos. A diferencia de otros países de la región, donde la presencia del capital estadounidense era fuerte desde mucho tiempo atrás, sobre 
todo por las bananeras, en El Salvador irrumpió con fuerza a partir de los años sesenta. La vinculación con el capital extranjero permite a sectores de la vieja oligarquía centralizar y concentrar fuertemente el capital, ampliándose a nuevas áreas de la producción y subordinando así el proyecto modernizante nunca completado. Esto explica que la única forma para contestar políticamente al control oligárquico sobre el Estado fuese la vía armada, pues los otros sectores sociales no podían participar de ninguna forma en el control del Estado, sometido a un férreo dominio de clase.

La izquierda nunca llegó a entender con claridad que lo que estaba en el centro de su lucha y de los apoyos sociales que recibía era la destrucción del Estado oligárquico en su carácter de instrumento de dominio de clase y reproductor de la sobreexplotación', y no el "sistema capitalista" tal como era visualizado ideológicamente en el discurso insurgente. Por eso, cuando el contexto internacional se modifica radicalmente con el fin de la guerra fría, en el análisis de Estados Unidos pierde fuerza la dimensión anticapitalista de la lucha insurgente y aquel país reubica el conflicto salvadoreño en su dimensión nacional y en sus raíces históricas: el carácter exclusivo y excluyente del Estado y del modelo de acumulación oligárquico.

\section{Los cambios en la derecha}

Con los acuerdos de paz, el Partido ARENA experimenta una transformación política de largo alcance: pasa de ser la representación estricta del modelo económico y político oligárquico de la clase dominante, que en los años ochenta fue oponente activo de las transformaciones contrainsurgentes promovidas por Estados Unidos, a asumir el papel político de garante del pacto de fondo implícito en los acuerdos de paz: ARENA acepta ser depositario de la ideología y del proyecto de Estados Unidos (el neoliberalismo, el ajuste estructural, las reformas institucionales), a cambio de seguir usufructuando el poder del Estado, lo cual le permite defender y reproducir las condiciones de centralización y concentración del capital en manos del sector económico dominante.

La vieja alianza de Estados Unidos con la oli- garquía tiene ahora una segunda edición con modificaciones significativas: la tierra redistribuida, la Fuerza Armada subordinada, libertad de información, pluralismo político y aceptación del papel político de la Iglesia. Una vez realizado el programa de ajuste estructural, la clase dominante se enfrenta a la definición de un nuevo modelo de acumulación.

Todo apunta a que la derecha en el poder tiene interés en subordinar aún más las estructuras económicas nacionales al sistema productivo norteamericano. Los nuevos ejes de la acumulación se encuentran centrados en lo financiero y en la distribución (comercio). El objetivo es convertirse en una clase rentista, conviertiendo al país en un centro de operaciones del capital globalizado: la maquila como alternativa al desarrollo industrial, y la transformación de El Salvador en la plaza financiera del espacio regional centroamericano, ofreciendo una estabilidad cambiaria y monetaria sobre la base de las reservas acumuladas a partir de las remesas de los emigrantes las cuales, previsiblemente, van a continuar al menos durante una década más. De esta forma, las remesas sirven, por un lado, como cobertura para las inversiones que el gran capital salvadoreño tiene en toda la región (café, turismo, distribución, comercio, construcción) y, por el otro y a mediano plazo, sirven para convertirse en el eje financiero del proceso de integración económica con México, Colombia y Venezuela, ante la perspectiva de la integración en el tratado de libre comercio de Norteamérica5.

El nuevo grupo dominante que controla el sistema financiero está subordinando a otros intereses particulares, especialmente los vinculados a la producción agrícola tradicional y a la industria nacional. Estos últimos, incapaces por ahora de articularse políticamente de forma autónoma, están cada vez más amenazados de extinción o, por lo menos, de marginación y exclusión por la aplicación y el desarrollo del nuevo proyecto de acumulación y dominación.

\section{Del Estado cafetalero al financiero}

El espacio nacional pierde interés específico 
como área fundamental de acumulación de capital para los grupos del capital transnacionalizados. Ahora el eje es regional y, en esta dimensión, El Salvador es fundamentalmente el lugar para captar las divisas que garantizan la necesaria estabilidad monetaria del nuevo modelo. Estos sectores pretenden adaptar el Estado a esta nueva realidad. No obstante, hay cierta continuidad con el Estado agroexportador, en el sentido de que el Estado funcional es el "Estado mínimo" en el cual las funciones de seguridad interna deben ser las estratégicas.

Los grupos dominantes necesitan controlar la acción del Estado porque, con las leyes nacionales actuales, las ganancias que obtienen con sus inversiones internacionales no están sujetas a la fiscalidad propia de un país desarrollado. Teniendo como base financiera y empresarial a El Salvador, estos grupos dominantes requieren un "Estado mínimo" especialmente en lo que se refiere a la fiscalidad de las sociedades y las rentas empresariales (esto explica la aceptación y anuencia de la corrupción, mecanismo que sirve para mantener altas tasas de ganancia y bajas tasas declaradas al fisco). Así se explica que este sector promueva el aumento de los impuestos al consumo (IVA) como un mecanismo para incrementar los recursos del Estado y no los impuestos sobre la renta personal y de las sociedades, y que se haya eliminado el impuesto al patrimonio, etc. Tratan de garantizar que El Salvador sea un paraíso fiscal para las empresas y que no exista un control adecuado sobre el manejo financiero (de allí la propuesta de eliminar el Banco Central de Reserva).

El control del Estado les es necesario también para implementar la privatización de las comunicaciones, un espacio de alianza con el capital transnacional que, además, permite ampliar la esfera de ganancias del capital rentista. Por ello se quedarán con una parte de las acciones, pero venderán otra al capital transnacional. De esta manera, se garantizan la necesaria modernización tecnológica y la ampliación de la cobertura y de la red de servicios. $Y$ así, sin ningún esfuerzo empresarial, salvo la prima a pagar por un paquete importante de acciones, se garantizan unas utilidades fijas que, suponiendo el control de un tercio de las acciones de ANTEL, no bajarían, en términos brutos (es decir, antes de los impuestos) de los 20 millones de dólares anuales)6.

Este grupo aspira también a controlar la gestión de los fondos del sistema de previsión social (la caja del Instituto Salvadoreño del Seguro Social y del Instituto Nacional de Pensionados Públicos) ${ }^{7}$. Esto supondría una importante inyección de fondos en el sistema financiero, ya controlado por ellos, y garantizaría una entrada permanente de dinero al pasivo, con el cual se aseguraría la expansión del sistema más allá de las fronteras nacionales.

El nuevo modelo de acumulación incluye la sustitución del gasto público social orientado a un Estado de bienestar por el gasto público focalizado (Fondo de Inversión Social) con una orientación asistencial. Así, el Estado ya no es promotor de inversiones, ni árbitro entre intereses, ni promotor de sectores sociales emergentes.

\section{Las contradicciones del proyecto dominante}

Ante este panorama cabe preguntar lo siguiente: ¿el grupo que está tratando de imponer el modelo de acumulación rentista y la regionalización del capital sobre la base de las inversiones comerciales y financieras, tendrá la capacidad para imponerse a los sectores agroindustriales y manufactureros? ¿Se mantendrá la alianza de este grupo con el capital comercial, si la apertura externa trae consigo la presencia e inversión de cadenas distribuidoras transnacionales (Sears, $A \& M$ ), incluso de las grandes cadenas mexicanas (Aurrera, Comercial Mexicana)?

Las contradicciones presentes en el sector dominante están llevándonos al centro del juego: el poder, quién manda. En este sentido, la disputa por el Estado y por la política económica es más profunda de lo que aparece en los medios de comunicación: el sector que domina en el ejecutivo no ofrece ningún espacio a la política de fomento $\mathrm{y}$, por lo tanto, al desarrollo del sector industrial y agropecuario. Su oferta hacia estos sectores se limita a recomendarles la "reconversión" de sus capitales productivos a capital rentista: transformar la industria textil nacional en maquila (alquilar 
maquinaria y mano de obra) e invertir las utilidades en el sector financiero, inmobiliario y comercial.

El grupo dominante cuenta con aliados diferentes. Por un lado, un sector de la clase media nacional -recordemos que la clase media es la que expresa la "opinión pública"- que, por su calificación profesional, participa en la gestión de los negocios financieros, inmobiliarios y del mismo presupuesto nacional y de la ayuda externa. Al mismo tiempo, el grupo dominante se ha creado una base social de apoyo entre los sectores populares a partir del uso clientelista de los fondos de compensación social y de reconstrucción nacional. En el espacio regional existe una alianza con grupos empresariales que participan de la lógica de la acumulación especulativa y financiera, dominante en todos los países, a partir de la implementación de los programas de ajuste estructural.

La confrontación entre los sectores económicos dominantes está dada por la existencia de formas diferentes de acumulación -especulativa, financiera, agroexportadora, manufacturera y comercial-y por el predomino mundial de las formas especulativas y financieras de acumulación, las cuales se imponen por medio de los programas de ajuste estructural y a nivel nacional se traducen en las políticas impulsadas desde el Estado.

En 1995 y probablemente también en 1996, las contradicciones por el control del Estado seguirán abiertas. Hay dos vías para resolver esta cuestión: la tradicional, y poco viable en la actual coyuntura, es llamar al ejército para dar un golpe de Estado en favor de uno u otro de los sectores en pugna. La otra vía es la del juego de alianzas. Por un lado, entre los afectados por el grupo rentista y financiero. Es el viejo estilo de resolución de las cuotas de poder entre los sectores capitalistas vía las gremiales empresariales. Pero cabe también la formación de nuevas alianzas con un componente más explícitamente político, si los sectores del capital afectados por la orientación actual del Estado se articulan con los agrupamientos políticos que puedan ofrecer alternativas nacionales, donde se inscriban sus intereses.

La inexistencia de un liderazgo político y las divisiones de la oposición permiten aventurar que la resolución de esta disputa se hará por la vía privada y no mediante la puesta en marcha de una alternativa pública nacional.

El papel del Estado en la coyuntura actual: la agenda estratégica

Ningún sector político de oposición, por sí mismo, es alternativa en la coyuntura actual, a no ser que pudiese crear condiciones para hacer alianzas estratégicas que recojan, dentro de una óptica capitalista, los intereses de los afectados entre los grupos subordinados del capital y los de la fuerza de trabajo. Se trataría de luchar porque el Estado no se transforme en ese instrumento subordinado al grupo financiero $y$ abanderar una alianza entre los productores nacionales y los asalariados, a nivel nacional y regional, para buscar otra perspectiva de desarrollo y de Estado.

En la transición, lo fundamental que está en juego es el carácter del Estado y de la reforma estatal: un Estado subordinado al esquema económico dominante (concentrador), es decir, un Estado mínimo tecnocrático o bien un Estado promotor de consensos, promotor de desarrollo y transformación social (gasto social y regulación económica), es decir, un Estado que contribuya a la transformación de la estructura de clases 8 e impulsor de nuevos agentes productivos (cooperativas, microempresarios).

Para que la oposición pueda aspirar a orientar la política gubernamental, debe proponer un nuevo modelo de acumulación y consensuar el papel del Estado. Solo así podría aspirar a participar en la orientación de la política gubernamental.

La acumulación que debe promocionarse mediante políticas adecuadas de fomento para los diversos sectores productivos - las cooperativas agrícolas, los productores agroindustriales, las actividades agropecuarias, artesanales y manufac-

\section{Las contradicciones presentes en el sector dominante están llevándonos al centro del juego: el poder, quién manda.}


tureras, los servicios productivos como la ingeniería, el agua, la energía y las comunicacioneses la acumulación nacional. Este conjunto de actividades permite ampliar la influencia más allá de la tradicional base de la oposición, centrada en la clase obrera, el campesinado pobre y los estratos minoritarios de la clase media.

El mercado interno tiene que ser el eje de un nuevo modelo de acumulación. Solo así se puede aspirar a tener algún control sobre la participación de El Salvador en la división internacional del trabajo en la era de la regionalización y la globalización. En efecto, el mercado externo al cual se puede dirigir la producción nacional es un mercado administrado, donde el volumen de exportación no depende tanto de la productividad comparativa como de la cuota a que se tiene acceso en el mercado de destino (textiles, azúcar) o a la cuota negociada en el correspondiente organismo regulador internacional (café).

Una de las tareas del Estado es, precisamente, desarrollar el mercado interno, generando los mecanismos - los incentivos para la producción y la regulación del mercado de trabajo- que permitan, por la vía de las políticas de empleo y de redistribución, ampliar la base del mercado doméstico hacia las mayorías pobres y excluidas, y mejorar la calidad de la oferta y de la demanda, mediante una mejora sostenida de la productividad y de los salarios reales. Además, la política centroamericana concertada entre los estados y los sectores sociales debe contribuir a transformar el espacio regional en mercado interno.

Desde esta perspectiva se debe hablar de "modernización del Estado", desarrollando las infraestructuras regionales (la red vial, el ferrocarril, la energía, el cuidado de las cuencas acuíferas), las políticas laborales, la política financiera, la política de seguridad social. Todas estas son tareas de lo estados. La aplicación de políticas de fomento productivo, de regulación del mercado de trabajo, de vigilancia para la existencia de mecanismos de competencia, etc., son tareas que requieren una ampliación de la calidad y de la cantidad de Estado.

Detrás de las denuncias y campañas sobre la corrupción en el Organo Judicial se está planteando la inadecuación de este órgano para afrontar las tareas de la nueva fase política y económica del país, donde la autonomía de los órganos del Estado es un requisito para regular un mercado político y económico de "libre competencia", donde el pluralismo de ofertas va a la par con la necesidad de transparencia en la información y la posibilidad de elección por parte de los consumidores y los votantes.

Esta perspectiva está ausente de la visión neoliberal que proclama la necesidad de un "Estado mínimo" y funcional para el modelo rentista financiero. La acumulación por la vía financiero especulativa es muy rápida, pero al mismo tiempo es muy frágil, pues depende de factores no controlables como son la entrada de divisas sin contrapartida o las políticas monetarias de los países desarrollados, en especial de Estados Unidos, que responden a su situación interna y no a las necesidades de las economías subdesamolladas que se encuentran "pegadas al dolar". Por el contrario, la apuesta por la economía nacional es más lenta, pero garantiza cierto grado de control interno sobre la coyuntura económica - una autonomía más asegurada en el plano re- 
gional- y al mismo tiempo, una mejora en los niveles de vida de la mayoría de la población.

\section{Crítica del Estado actual}

El programa de ajuste estructural, tal como fue concebido para el primer gobierno de ARENA, se cumplió en un 80 por ciento. Tan solo la parte correspondiente a la "modemización del Estado" quedó entrampada, sin que avanzara sustancialmente, a pesar de las presiones de los organismos internacionales, especialmente del Banco Mundial, el Programa para el Desarrollo de Naciones Unidas y también de la Agencia Internacional para el Desarrollo.

Hasta ahora se desconoce la existencia de un proyecto global y coherente para reformar el Estado por parte del gobierno. Sólo aparecen reiteradamente dos ideas, con un contenido más ideológico y político que técnico: la modernización del Estado se identifica fundamentalmente con la reducción de personal y la privatización de áreas básicas del sector público9.

En lo que respecta a la reducción del Estado, los sectores más esclarecidos del equipo de gobierno son conscientes de que el Estado salvado- reño es muy pequeño y que la modificación de su comportamiento y su papel estructural requieren, necesariamente, un fortalecimiento del mismo 10 .

Toda la información disponible señala una fuerte correlación entre la dimensión del gasto público y los niveles de desarrollo. Como podemos ver en el cuadro y en el gráfico adjuntos, en América Latina, los países más avanzados tienen niveles de participación del gasto público en el producto interno bruto equivalentes a los de los países desarrollados. En Centroamérica, El Salvador tiene los niveles de gasto público más reducidos.

El Estado es, ciertamente, bastante más que el gasto administrativo. El discurso liberal critica propagandísticamente a la burocracia - para en la práctica incrementarla, pues la desregulación es más costosa en términos de personal dedicado a la misma que la propia regulación - para atacar después las actividades productivas del Estado. El objetivo no es eliminar las actividades ineficientes del Estado, sino capturar las empresas eficientes, para volverlas un recurso disponible al servicio de la valorización directa del capital (privado y en general transnacional).

Gasto público por habitante, segun países y regiones, 1992

\begin{tabular}{lrrrrrr}
\hline & $\begin{array}{c}\text { Población } \\
\text { (millones) }\end{array}$ & \multicolumn{1}{c}{ PIB } & $\begin{array}{c}\text { Gasto } \\
\text { público }\end{array}$ & $\begin{array}{r}\text { PIB per } \\
\text { capita }\end{array}$ & $\begin{array}{c}\text { Gasto } \\
\text { público } \\
\text { per capita }\end{array}$ & $\begin{array}{c}\text { Gasto } \\
\text { público/PIB } \\
\%\end{array}$ \\
\hline Estados Unidos & 255.4 & $5,920,199$ & $1,438,608$ & 23,180 & 5,633 & 24.3 \\
Unión Europea & 331.1 & $6,662,867$ & $2,656,225$ & 20,123 & 8,022 & 39.9 \\
Japón1 & 124.5 & $3,670,979$ & 580,015 & 29,486 & 4,659 & 15.8 \\
Cono sur & & & & & & \\
Sudeste asiático3 & 310.8 & 28,1502 & 60,913 & 5,653 & 1,223 & 21.6 \\
Nicaragua & 3.9 & 505,530 & 98,732 & 1,626 & 318 & 19.5 \\
Honduras & 5.4 & 1,847 & 726 & 474 & 186 & 39.3 \\
Guatemala & 9.7 & 10,434 & 1,252 & 1,076 & 129 & 16.1 \\
Costa Rica & 3.2 & 6,530 & 1,815 & 2,041 & 567 & 27.8 \\
Centroamérica & 22.2 & 21,624 & 4,246 & 974 & 191 & 19.6 \\
El Salvador & 5.4 & 6,443 & 722 & 1,193 & 134 & 11.2 \\
\hline
\end{tabular}

1 Solamente datos de las cuentas presupuestarias.

2 Chile, Argentina, Uruguay.

3 Indonesia, Filipinas, Malaysia, Corea.

Fuente: Banco Mundial, Informe sobre el desarrollo mundial 1994. 
Gasto público por habitante 1992



Participación del gasto público en el PIB (en \%)

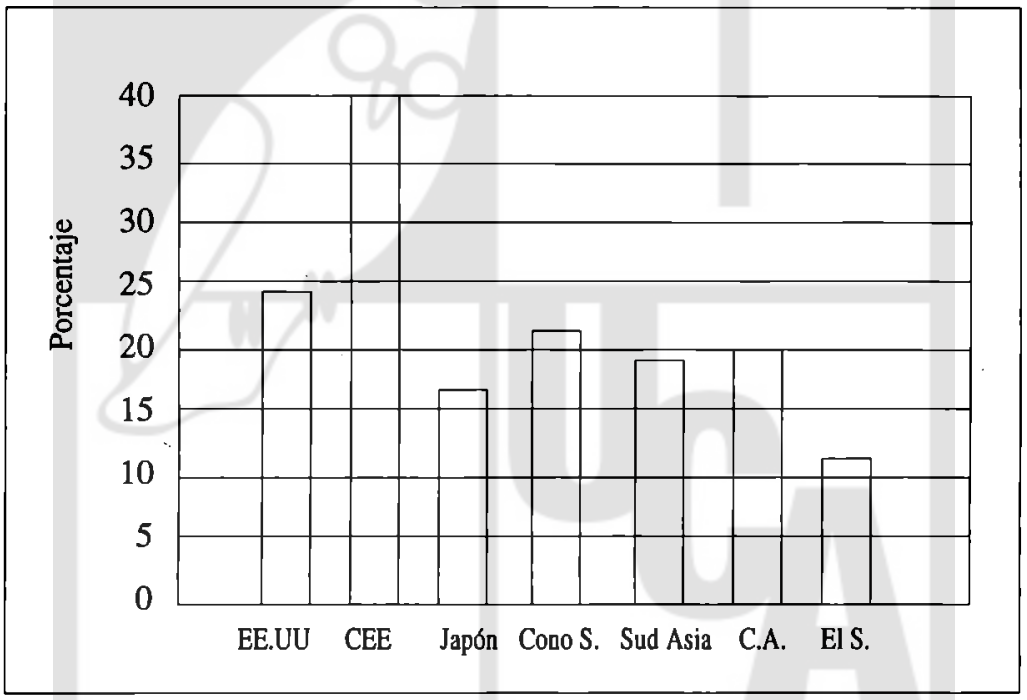

Actualmente están planteadas las siguientes privatizaciones: ANTEL, CEL, CEPA, Caja de ISSS, Caja del INPEP, aduanas, servicios (construcción de infraestructura, servicios de mantenimiento, etc.), atención primaria en salud y especialidades hospitalarias. Y continúa el proceso de privatización de los servicios educativos (ENA, INSAFORP), de la asistencia técnica (CENTA) y otros.

El modelo de reforma planteado, orientado fundamentalmente a la privatización del gasto público, es reproducción del modelo híbrido dominante: el nivel del gasto público se mantiene e incluso se eleva, pero la gestión se pasa al capital11, 


\section{El objetivo real de la privatización es lograr que algunos grupos de poder articulados al partido ARENA controlen activos de alta rentabilidad sin realizar ninguna inversión efectiva.}

el cual puede establecer, en casos específicos, mediante mecanismos de colusión con el Estado, rentas de monopolio.

Para promover las privatizaciones, el gobierno argumenta que es un mecanismo adecuado para obtener liquidez y financiar el gasto social. Este argumento, que puede funcionar como mecanismo para controlar a la opinión pública, no se sostiene técnicamente: las utilidades de las empresas públicas son permanentes y los ingresos de su venta se obtienen en un sólo momento. $\mathrm{Al}$ margen que, tal como está planteada realmente la privatización, el precio de venta estimado, por ejemplo, de ANTEL es inferior a la rentabilidad financiera de su flujo de caja actual, confirmando así que el objetivo real de la privatización es lograr que algunos grupos de poder articulados al partido ARENA controlen activos de alta rentabilidad sin realizar ninguna inversión efectiva (tal como ocurrió con la privatización bancaria). Lo mismo sucede con las cajas del seguro social y del Instituto Nacional de Pensionados Públicos. El objetivo es incrementar el volumen de los depósitos de la banca privada, manejando discrecionalmente unos fondos de inversión garantizados, en última instancia, por el Estado. ¡De nuevo, el mercado se apuntala en el Estado para poder funcionar realmente!

La modernización del Estado, desde el punto de vista del desarrollo, no tiene nada que ver con lo planteado por el gobierno. De hecho, no es tanto un problema de dimensión, como de funciones: el Estado ha fracasado en América Latina como agente del desarrollo por sus limitaciones para encabezar la transformación de la estructura de clases y de la estructura productiva. La lucha por la hegemonía dentro de la clase dominante entre los intereses oligárquicos tradicionales y los de un capitalismo modernizador, tropezó con el tipo de inserción en la estructura mundial de nuestro continente. La subordinación al capital financiero internacional de los estados locales, se tradujo, con la crisis de la deuda, en la derrota de los intereses modernizantes. Allí donde se llegó a instalar un proyecto popular para manejar el Estado, éste fue confrontado y derrotado por la alianza entre el imperialismo y las clases dominantes locales (Chile, Nicaragua y, en cierta medida, el Perú de Alan García), derrota facilitada. por las restricciones específicas a cada proyecto de gobierno popular.

\section{Propuesta de Estado}

Dentro de la sociedad salvadoreña se ha constituido una economía fundamentalmente capitalista $y$, por esta razón, han surgido y coexisten contradictoriamente diversas clases sociales que sustentan y defienden intereses particulares, generándose así la conflictividad social permanente que ha caracterizado históricamente a El Salvador.

En este contexto, entre los grupos de propietarios se ha desarrollado la lucha por controlar el poder del Estado con la finalidad de utilizarlo como instrumento de dominación y de acumulación de capital, tal como lo hemos analizado. De esta manera, los intereses grupales predominantes en determinados momentos de la vida del país han sido planteados a la población como los intereses generales de la nación, obviamente, con el propósito de legitimar su dominio, y han sido defendidos con diversas formas y medios cuando fueron cuestionados por una parte de la sociedad, tal como lo evidenció la guerra civil de los últimos quince años.

La noción del poder del Estado como botín a capturar, presente en la clase social dominante articulada en sectores y grupos económicos diferenciados por las diversas formas de propiedad que utilizan para sus procesos de acumulación-. tradicionalmente "conductora" del país, debe ser superada por el conjunto de los otros sectores sociales, cuyo interés es fortalecerse económica y políticamente y abrirle paso a una nueva 
concepción del Estado que, partiendo de la existencia de las clases sociales con intereses contradicctorios, en nuestro país, se instituya en instancia e instrumento de la sociedad con la definición, vocación y capacidad de promover, producir y sostener los consensos, las concertaciones, los acuerdos y pactos necesarios para canalizar el constante conflicto de intereses, evitar el dominio de una clase social sobre el resto de la sociedad, construir un proyecto nacional basado en la práctica de la democracia, potenciar la organización de la sociedad civil y cumplir y hacer cumplir el cuerpo legislativo que derive de esta nueva concepción del Estado.

Se trata de que en la nueva fase histórica de nuestro país tengamos como estrategia la construcción de un Estado concertador, democrático y social. Es decir, que el pueblo entre en el Estado -más que llevar el Estado al pueblo-, lo que implica la creación de un marco general de participación social en la definición de las políticas del Estado que apunten, en definitiva, a la formulación de los perfiles básicos de lo que los salvadoreños entenderemos y sustentaremos como "desarrollo", en relación con la calidad de vida que queremos en nuestro país y de la cual podamos sentirnos satisfechos como nación.

En concordancia, entendemos que el Estado salvadoreño debe fundamentarse políticamente en la estructuración de los tres poderes tradicionales y de otros nuevos que se consideren necesarios por ejemplo, el Tribunal Supremo Electoral, la Contraloría General de la República, la Procuraduría de los Derechos Humanos u otros, que deberían ser de elección popular o al menos ser elegidos por los representantes en el Organo Legislativo-, como contrapesos mutuos que eliminen la posibilidad que los grupos con vocación hegemónica - la oligarquización del poder-, que instrumentalizan las instituciones estatales - la corrupción- en función de intereses particulares controlen el poder político.

Implicaría, por lo tanto, la redefinición de las áreas de competencia de los órganos del Estado, sus funciones $\mathrm{y}$ formas democráticas para acceder a la dirección y conducción de los mismos. Por ejemplo, la conversión de la polícía en policía ju-

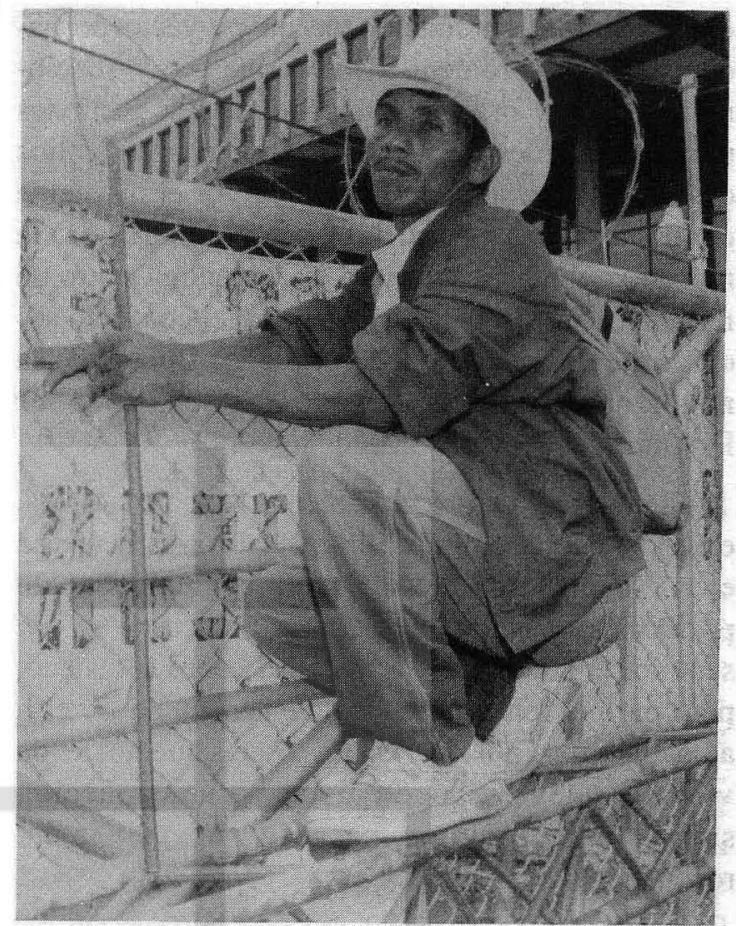

dicial, sometida al Organo Judicial y no al Ministerio del Interior, el control judicial de los centros penitenciarios, el nombramiento de los jueces por oposición y no por compadrazgo, la creación de un tribunal constitucional, el Tribunal Supremo Electoral debe controlar y desarrollar el registro civil, creando el número único para cualquier actividad (cédula de identidad, seguro social, carnet electoral, NIT, etc.). La asamblea legislativa debe tener autonomía para crear su propio cuerpo legislativo y no sólo a iniciativa del ejecutivo, debe participar más activamente en la definición de la estructura del presupuesto público y en la definición de las políticas de ingreso y gasto público. Una institución autónoma debe centralizar la recolección y el procesamiento de los censos y las estadísticas económicas, sociales y demográficas. Los órganos de participación política - los consejo municipales con participación de la oposición, las cámaras departamentales o regionales - deben ser ampliados.

La perspectiva que guiaría esta refundación del Estado es convertir la acción coyuntural de las políticas del Organo Ejecutivo, basado en un presidencialismo anacrónico, en políticas de Esta- 
do, orientadas en función de un proyecto de nación que comprometa a los dirigentes y funcionarios de los órganos en conductas y gestiones públicas acordes con los objetivos nacionales, los cuales siempre serán contrariados por el insistente conflicto social -y su histórica contrapartida: la represión abusiva, autoritaria y violenta. Dentro de nuevas reglas de convivenia social, el conflicto social será encauzado hacia los sabios límites de la negociación que un Estado fuerte - por ser legítimo - puede garantizar.

La relación entre el Estado y la sociedad será, entonces, no la dominación que históricamente ha ejercido el primero sobre la segunda, sino la posibilidad para practicar la democracia $y$, en ese sentido, el control de la sociedad sobre el Estado, pero en una relación dialéctica, sometiéndose ésta a las normas por las cuales precisamente le da vida al nuevo tipo de Estado que la nación salvadoreña requiere para su supervivencia, reconstrucción y desarrollo.

\section{Conclusión}

El problema principal de la coyuntura de transición en el país es la construcción de un Estado nuevo que debe organizarse para llevar adelante los acuerdos de paz, realizar la transformación económica y establecer la vigencia del Estado de derecho.

La hegemonía de Estados Unidos se traduce en la aplicación de un modelo económico neoliberal que refuerza la dependencia política y económica, volviendo problemático el ejercicio de la soberanía nacional y manteniendo las estructuras del Estado subordinadas a los intereses de los grupos dominantes del capital salvadoreño, los cuales se encuentran en una fase de transnacionalización.

Las disputas entre los sectores de la derecha son expresión de contradicciones reales en cuanto a la acumulación del capital y de la debilidad democrática del sistema, por cuanto reflejan que los problemas del poder no se resuelven por la competencia de las estructuras partidarias por medio de programas, sino en el viejo estilo, dentro de las cúpulas gremiales de los empresarios. La ausencia de un programa de gobierno en los primeros meses de la presidencia de Calderón Sol evidencia la diputa interna entre las diversas fracciones del capital, que aún no se ponen de acuerdo sobre las formas y los contenidos de la gestión de los recursos del Estado.

La formulación de un proyecto nacional tiene que incorporar como un aspecto básico la definición del Estado que debe existir en la sociedad salvadoreña. Sólo una redefinición del Estado y su papel histórico pueden superar el carácter patrimonial que siempre aquél ha tenido en el país. Sólo un Estado democrático puede garantizar una concertación de intereses que vaya más allá de las disputas internas del capital y la incorporación de los sectores tradicionalmente marginados de la acción del Estado (salvo la represiva) en la discusión de las decisiones nacionales.

La agenda política del momento está marcada por la opción entre la reproducción de un Estado de clase y para la clase (dominante) o la creación de un Estado democrático capaz de canalizar por vías civiles el conflicto inherente a la sociedad capitalista.

Sólo el fortalecimiento de una "clase política" civil y autónoma respecto a los intereses inmediatistas del capital que tradicionalmente ha usufructuado la acción del Estado, pero también de los intereses corporativistas de las clases subalternas, podría garantizar que los intereses nacionales priven sobre los intereses de grupo y, por lo tanto, diseñar políticas de Estado que superen el corto plazo de las políticas de gobierno.

El tamaño del Estado o las privatizaciones no son ni la alternativa ni la discusión fundamental sobre el problema. Las fuerzas políticas y sociales del país están obligadas a tomar posición sobre la necesidad de refundar el Estado desde la perspectiva del desarrollo económico y social, para propiciar un nuevo modelo de acumulación de capital y de redistribución de la riqueza nacional (activos productivos e ingreso). 
Notas

1. En este contexto, hoy en día, la discusión de alternativas se da únicamente entre modelos capitalista liberales y modelos capitalistas redistributivos, con una clara ventaja actual de los primeros.

2. El Estado, tal como lo estamos entendiendo en ese modelo de acumulación, se entiende como la conjunción de sus tres poderes -el judicial, el legislativo y el ejecutivo-, cuya orientación común apunta esencialmente a defender la propiedad privada y el orden establecido.

3. La aparición, a mediadas de los años sesenta, de un nuevo actor social, la clase obrera, y en los setenta, de nuevos actores políticos, las clase medias -los profesionales, los medianos empresarios- y los sectores populares (Partido Demócrata Cristiano, Movimiento Nacional Revolucionario, Partido Comunista y posteriormente los partidos armados) modificó las estructuras del Estado, que pasaron de ser esencialmente represivas a ser básicamente contrainsurgentes (doctrina de la seguridad nacional).

4. Entendemos por "sobreexplotacion" de la fuerza de trabajo, una situación en la cual el nivel de los salarios no tiene ninguna vinculación con el nivel de productividad ni permite cubrir la totalidad de los costes de la reproducción de la fuerza de trabajo. En estas circunstancias, el proceso de acumulación requiere un elevado volumen de mano de obra desempleada para sustituir constantemente a los trabajadores ocupados.

5. Este último objetivo requiere aún ciertos cambios institucionales. En primer lugar, es necesario crear una bolsa de valores a nivel centroamericano y, en segundo lugar, unificar los mercados financieros de la región en materia de tasas de interés y gestión bancaria

6. Según fuentes de la empresa, ANTEL obtuvo en 1992 unas utilidades brutas de 525 millones de co- lones, al cambio unos 63 millones de dólares. Ver el documento: "Gobierno de El Salvador: plan quinquenal 1994-1999”, 1993, p. 134.

7. Sin embargo, ningún documento oficial propone privatizar el fondo de pensiones de la Fuerza Armada (IPSFA), por ser coto exclusivo del Estado Mayor.

8. En El Salvador, el Estado ha sido el creador de las clases sociales: la clase media (los profesores, los abogados, los médicos y las enfermeras) ha sido creada al amparo del empleo público; la oligarquía se creó mediante el uso del Estado para expropiar las tierras nacionales (comunales y ejidales), etc.

9. Ver por ejemplo "Plan de gobierno republicano nacionalista 1994-1999", pp. 27-31, s.f.

10. Por ejemplo el actual Ministro de Hacienda, Manuel Enrique Hinds: “el tamaño del gobierno de El Salvador es uno de los más pequeños en el mundo... cuando nosotros hablamos de la modernizacion del Estado, nosotros no estamos hablando de achicar el Estado" ("Entrevista Al Día", Canal 12, 23 de enero de 1995). En todo caso, estas declaraciones contrastan abiertamente con los documentos del gobiemo actual y especialmente del anterior, que explícitamente declaraban como uno de sus objetivos prioritarios "reducir el tamaño del Estado" (ver "Plan de desarrollo económico y social 1989-1993", MIPLAN-GAES, 1990).

11. Por ejemplo, la educación de los trabajadores esta en manos de FEPADE y de las gremiales empresariales por medio del INSAFORP; Ia capacidad instalada en maetria de investigación y desarrollo agrícola ha pasado a manos de los cafetaleros (ISIC y PROCAFE) y del capital en general (privatización del CENTA y ENA); la obra civil en materia de telecomunicaciones ha pasado a manos de las multinacionales (ERICSSON, ALCATEL, SIEMENS); la salud laboral cuya protección es tarea del Estado, está en manos de los empresarios a través de la fundación FIPRO, etc. 